\title{
Effect of Technology in Sedentary Lifestyle and its Impact on the Overall Well Being of the it Employees in Chennai
}

\author{
D. Anithakumari, S. Gayathri, G. Ramya
}

\begin{abstract}
The employees of the corporate world spend most of their office hours at their table. It is no wonder, that the office environment is sedentary. After a long day work, there is very less chance that the employee finds time for healthy physical activity. Employees are involved in a sedentary lifestyle, and are bound to have a negative impact over health leading to psychological stress and many other physiological problems. This paper concentrates on bringing out the impacts of sedentary lifestyle among IT employees with reference to Chennai. Besides in sedentary lifestyle, practices such as no appropriate balanced diet, intake of more junk foods and less consumption of water marks them to encounter many other health hazards which also is considered in the study. The study is descriptive in nature and has been conducted among a sample size of 180.Chi-square analysis and correlation analysis were used to interpret the results. Thus organization should make some corrective actions to help the employees to save them from being subjected to continual sedentary lifestyle. The employees need to take necessary measure to use the facilitations given by the organization. Thus a brief analysis on the ill health issues as an effect of technology and the ignorance by the employees is made and offered for supplementary analysis.
\end{abstract}

Key words: sedentary, lifestyle, stress, health, implication, IT professionals.

\section{INTRODUCTIONTO SEDENTARY LIFESTYLE}

Over the last 10 to 15 decades, there is a massive like manufacturing, walking on building constructions, farming are rehabilitated to office desk jobs. This is the fright to the sedentary lifestyle jobs. Sedentary lifestyle leads to increased BMI and thus human being are subjected to obesity or over weight. There is lack or deficiency in regular physical activity that causes premature death which is one of the greatest ill hazards that has to be considered. Researchers have demonstrated that proper physical activity can reduce the risk of many cardio vascular disease, diabetes and overweight or obesity. Thus the practice of this kind of sedentary lifestyle is becoming a public health issue which

Revised Version Manuscript Received on August 19, 2019.

Dr. D. AnithaKumari,Assistant Professor, Department of Management Studies, Vels Institute of Science, Technology\& Advanced Studies (VISTAS), Pallavaram, Chennai, Tamilnadu, India.(Email: anitha.sms@velsuniv.ac.in)

Dr.S.Gayathri, Associate Professor, Department of Management Studies, Vels Institute of Science, Technology\& Advanced Studies (VISTAS), Pallavaram, Chennai, TamilNadu, India.(Email: gayathri.sms@velsuniv.ac.in)

Mrs.G.Ramya,M.Phil. - Research Scholar, School of Management Studies, Vels Institute of Science, Technology\& Advanced Studies (VISTAS), Pallavaram, Chennai, TamilNadu, India.(Email:ramyagk26@gmail.com) significant transformation in the nature of human labor jobs

should be considered in a vast mode. Sedentary lifestyle also has a huge impact on the mental health which leads to psychological stress or insomnia (sleeplessness) and many other mental issues. Prolonged physical inactivity also leads to poor rate of metabolism which is the origin to the poor BMI rate. In recent days researches reveal that sedentary lifestyle also leads to infertility both in male and female. Thus the sedentary lifestyle has many considerable health impacts which has to be sorted using the necessary alternative like engaging in regular physical activity like walking, yoga, cycling, etc. so as to reduce the risks over the sedentary lifestyle. This paper discusses the cause, impacts, and the effects of sedentary lifestyle and provides the necessary remedial actions that can be performed to reduce the health risks of the sedentary lifestyle.

\section{OBJECTIVES OF THE STUDY}

- To analyse the relationship between sedentary lifestyle and elevated psychological stress

- To comprehend the impact of sedentary behaviour and its ill health effects

- To study and recognize the actual concept and the significance of sedentary lifestyle

- To provide valid suggestions to overcome the ill health hazards of the sedentary lifestyle

- To create an awareness about the consequences of the sedentary lifestyle by disseminating the outcomes to IT employees.

\section{NEED FOR THE STUDY}

The rate of disease is increasing high. Diabetes, stress related health issues, blood pressure related problem like hypertension etc. are found to be increasing in the younger generation. The critical problem is increasing, now a days there is fertility problem in both men and women. Many don't commit themselves to regular physical activity as they find it ineffective to make a proper work life balance. Thus this study is needed to analyze and sort out all the problems related to sedentary behavior among the IT employees

\section{SCOPE OF THE STUDY}

This study is beneficial to both the employees and the 
organization as this creates awareness over the impacts of the sedentary lifestyle and the remedial corrective measures that can be implemented. As the employees are considered to be the great asset to the organization it is the responsibility of the organization to implement wellbeing actions to the employees. The organization could help their employees by providing physical activity outlets or centers for recreational activities etc. This study also creates a consciousness on the employees over their sedentary behavior and its effects which they are supposed to recognize. Thus in this way this study helps to identify and implement the remedial actions on sedentary lifestyle.

\section{REVIEW OF LITERATURE}

Dr.Mfrekemfon.P. Inyang and Okey-Orji Stella (2015) have briefly conferred the factors that involve and enhance the sedentary lifestyle. These factors enhancing sedentary lifestyle also deduces the various health hazards in adopting the sedentary lifestyle. This paper concluded stating various intended physical activities has to be worked out to avoid those health risks and suggested that the work place and public place has to be structured accordingly which could reinforce active movements and recreational activities. Dr.Seema G Chawardol, Dr. BhagwatiTripathi (2018) enumerated the sleeping disturbances associated with the sedentary lifestyle and also has conveyed the Ayurveda remedies and dietary supplements to manage healthy sleeping habits. This paper has also bought out the other causes of insomnia and the faultless ways to treat insomnia associated with sedentary lifestyle. Larissa CasteloGuedes Martins, Marcos Venicios de Oliveira Lopes(2015) made cross sectional study among the patients with hypertension and identified the significant cursors as the inference of sedentary lifestyle and also the feasible casual factors of the sedentary lifestyle. Margot Shields and Mark S. Tremblay (2008) studied and inferred the results on the predominance of obesity due to sedentary health practices among the people of all ages. This was a huge study involving around $42 \mathrm{~K}$ respondents among the entire population of Canada. The author has inferred that regular computer users at the average of 5 hours per day are subjected and experience obesity or other BMI related problems. Andre Ramalho and Joao Petrica(2018) computes and reveals that more research is needed of sedentary behavior for better understanding and to get to a conclusion on sedentary behavior. The author has targeted over the elderly people and has interpreted that there is no significant difference to be considered on sedentary behavior among the elderly people and suggest that certain sedentary practices would be helpful in maintaining the intellectual function among the elderly population.

Leandro Fornias Machado de Rezende, Mauricio
Rodrigues Lopes (2014) evaluated the significant systematic reviews of sedentary lifestyle and its outcomes on the health perspective. The author has interpreted that children and adolescent have a strong relationship on the time spent on sedentary behavior and obesity and has revealed the result and states that further study is merited. HarriHelajarvi (2016) intents to identify the association of sedentary behavior with obesity and weight increase and has also investigated the relationship between sedentary behavior and fatty liver. The author adopted interventional studies to analyze and has obtained a positive association on the above stated aspects.

\section{STATEMENT OF THE PROBLEM}

The job nature of the IT employees is strictly subjected to sedentary practices as they are subjected to work over the computer over their whole working day. The implementation of physical activities in between the work seems to highly impossible. Thus there is no choice for them to get rid of the ill health effects. Thus in current situation it is highly essential to find out the impact of the sedentary lifestyle on the IT employees.

\section{RESEARCH GAP}

There are enormous studies in the impact of sedentary lifestyle in many other aspects like psychological studies, medical implications which act as one of the cause for the chronic disease and many other stress related effects to humans. Thus there is no specific study sedentary behavior on the IT employees and is yet to be studied and needs huge data to analyze the actual problem. The IT industry is always booming over the last few decades, and huge number of employees are committed to work in the IT industry. These employees are subjected to ethical consideration over their health and wellbeing. And hence study on this is highly necessary to take and perform the remedial actions and to avoid the negative health impacts of the sedentary lifestyle.

\section{RESEARCH METHODOLOGY}

Descriptive research design has been applied in this study. Convenience sampling technique is used under non probability sampling technique to collect the samples. Sample size is 180. Primary data collected through questionnaire. 180 IT professionals were met in Chennai. Employees from leading MNC software solutions like TCS CTS, Wipro, Accenture, HCL, Infosys, Tech Mahindra, Capgemini, Virtusa Polaris were pursued to the survey. The tools used for data analysis are, Percentage analysis, Chi-Square Analysis and Correlation analysis. 
Table no 1: Percentage Analysis Of Demographic Variables

\begin{tabular}{|c|c|c|c|}
\hline QUESTION & VARIABLES & FREQUENCY & PERCENTAGE \\
\hline \multirow{3}{*}{ Genders } & Male & 107 & 59.7 \\
\hline & Female & 73 & 40.6 \\
\hline & Total & 180 & 100 \\
\hline \multirow{6}{*}{ Age } & $20-25$ Yrs. & 32 & 17 \\
\hline & 26 - 30 Yrs. & 48 & 27 \\
\hline & 31 - 35 Yrs. & 41 & 23 \\
\hline & 36 - 40 Yrs. & 38 & 21 \\
\hline & Above 40 Yrs. & 21 & 12 \\
\hline & Total & 180 & 100 \\
\hline \multirow{6}{*}{ Experience } & $0-2$ years & 47 & 26 \\
\hline & $2-5$ years & 57 & 32 \\
\hline & 5-10 years & 37 & 21 \\
\hline & $11-15$ years & 23 & 13 \\
\hline & 15 years and above & 16 & 08 \\
\hline & Total & 180 & 100 \\
\hline \multirow{4}{*}{ Education } & Diploma & 30 & 17 \\
\hline & Under Graduate & 98 & 54 \\
\hline & Post Graduate & 52 & 29 \\
\hline & Total & 180 & 100 \\
\hline \multirow{4}{*}{ Marital status } & Single & 78 & 43 \\
\hline & Married & 97 & 53 \\
\hline & Others & 05 & 04 \\
\hline & Total & 180 & 100 \\
\hline \multirow{5}{*}{ No. of Children } & 0 & 106 & 59 \\
\hline & 1 & 62 & 34 \\
\hline & 2 & 9 & 5 \\
\hline & 3 & 3 & 2 \\
\hline & Total & 180 & 100 \\
\hline \multirow{6}{*}{ Monthly Income } & Below 20,000 & 12 & 7 \\
\hline & 20,001 to 30,000 & 41 & 23 \\
\hline & 30,001 to 40,000 & 52 & 29 \\
\hline & 40,001 to 50,000 & 42 & 24 \\
\hline & 50,001 and above & 33 & 17 \\
\hline & Total & 180 & 100 \\
\hline
\end{tabular}

\section{Source: Primary data}


Table no : 2 Chi Square Test

\begin{tabular}{|c|c|c|c|c|c|}
\hline $\begin{array}{l}\text { S. } \\
\text { No }\end{array}$ & Chi square between & $\begin{array}{l}\text { P- } \\
\text { value }\end{array}$ & $\begin{array}{l}\text { Sig.2-sid } \\
\text { ed }\end{array}$ & Accepted & Result \\
\hline 1 & $\begin{array}{l}\text { Gender *I am highly stressed due } \\
\text { to the sedentary work style I am } \\
\text { undergoing }\end{array}$ & $3^{a^{a}} 11.37$ & .010 & $\begin{array}{l}\text { Null Hypothesis } \\
\text { (Ho) }\end{array}$ & $\begin{array}{l}\text { No Significant } \\
\text { relationship }\end{array}$ \\
\hline 2 & $\begin{array}{l}\text { Gender *I believe that regular } \\
\text { exercise or physical activity could } \\
\text { make me stay healthy }\end{array}$ & $\begin{array}{ll} & 7.862 \\
\text { a }\end{array}$ & .044 & $\begin{array}{l}\text { Null Hypothesis } \\
\text { (Ho) }\end{array}$ & $\begin{array}{l}\text { No Significant } \\
\text { relationship }\end{array}$ \\
\hline 3 & $\begin{array}{l}\text { Education } * \text { I utilize my lunch } \\
\text { hour ignoring stress and getting rid of } \\
\text { sedentary lifestyle. }\end{array}$ & $4 a^{19.14}$ & .014 & $\begin{array}{l}\text { Null Hypothesis } \\
\text { (Ho) }\end{array}$ & $\begin{array}{l}\text { No Significant } \\
\text { relationship }\end{array}$ \\
\hline 4 & $\begin{array}{l}\text { I am obese person who weighs } \\
\text { more than I actually require. BMI * } \\
\text { kind of snacks you go for during your } \\
\text { munch breaks }\end{array}$ & $9 a^{16.67}$ & .052 & $\begin{array}{l}\text { Null Hypothesis } \\
\text { (Ho) }\end{array}$ & $\begin{array}{l}\text { No Significant } \\
\text { relationship }\end{array}$ \\
\hline 5 & $\begin{array}{l}\text { Age * I make a perfect work life } \\
\text { balance between my work and my } \\
\text { personal preferences on employees } \\
\text { to search new values and thoughts }\end{array}$ & 13.92 & .605 & $\begin{array}{c}\text { Alternative } \\
\text { Hypothesis (H1) }\end{array}$ & $\begin{array}{l}\text { Significant } \\
\text { relationship }\end{array}$ \\
\hline 6 & $\begin{array}{l}\text { Marital status } * \text { Engage myself in } \\
\text { physical activity }\end{array}$ & $\begin{array}{l}9.824 \\
\mathrm{a}\end{array}$ & .073 & $\begin{array}{c}\text { Alternative } \\
\text { Hypothesis (H1) }\end{array}$ & $\begin{array}{l}\text { Significant } \\
\text { relationship }\end{array}$ \\
\hline
\end{tabular}

\section{DISCUSSION OF RESULTS}

The above chi square indicates that there is no relationship in the middle of the underneath factor means. Both male and female representatives are worried because of stationary way of life. Regardless of sex, each representative trusts that customary exercise or physical action could make them remain sound, qualification assumes in using lunch hour to get rid of pressure and disposing of inactive way of life. Age is the main consideration to make an ideal work life balance between work and own inclinations on representatives to look new qualities and contemplations and there is a distinction among single and wedded workers in connecting with themselves in every day physical action.

Table no 3: Correlation Analysis

\begin{tabular}{|c|c|c|c|c|c|}
\hline $\begin{array}{l}\text { S. } \\
\text { No }\end{array}$ & Correlation between & $\begin{array}{c}\text { Pearson } \\
\text { Correlation }\end{array}$ & $\begin{array}{l}\text { Asym } \\
\text { p. Sig. } \\
\text { (2-sided) }\end{array}$ & Accepted & Result \\
\hline 1 & $\begin{array}{l}\text { Gender } * \text { Experience fatigue or } \\
\text { tired after work hours }\end{array}$ & .137 & .074 & $\begin{array}{c}\text { Alternative } \\
\text { Hypothesis (H1) }\end{array}$ & $\begin{array}{l}\text { Significant } \\
\text { Positive } \\
\text { relationship }\end{array}$ \\
\hline 2 & $\begin{array}{l}\text { Gender* Aware sedentary } \\
\text { lifestyle causes huge ill impacts, } \\
\text { physically and psychologically }\end{array}$ & $.321 * *$ & .000 & $\begin{array}{l}\text { Null } \\
\text { Hypothesis(H0) }\end{array}$ & $\begin{array}{l}\text { No Significant } \\
\text { Positive } \\
\text { relationship }\end{array}$ \\
\hline 3 & $\begin{array}{l}\text { Education* Sedentary life style is } \\
\text { associated with elevated perceived } \\
\text { stress }\end{array}$ & -.120 & .110 & $\begin{array}{l}\text { Null } \\
\text { Hypothesis(H0) }\end{array}$ & $\begin{array}{l}\text { No Significant } \\
\text { Positive } \\
\text { relationship }\end{array}$ \\
\hline 4 & $\begin{array}{l}\text { Age* Generous in spending time } \\
\text { mandatorily for their physical } \\
\text { exercise, yoga, aerobics, zumba or } \\
\text { any other calorie burning activities. }\end{array}$ & -.086 & .250 & $\begin{array}{c}\text { Alternative } \\
\text { Hypothesis (H1) }\end{array}$ & $\begin{array}{l}\quad \text { Significant } \\
\text { Positive } \\
\text { relationship }\end{array}$ \\
\hline
\end{tabular}

\section{DISCUSSION OF RESULTS}

The above correlation analysis states that there is a positive relationship between gender and experience. Alternative hypothesis is accepted at the level of significance is .074 , there is a positive relationship between age and generous in spending time mandatorily for physical exercise, yoga, aerobics, zumba or any other calorie burning activities and it 
gender and awareness that sedentary lifestyle causes huge ill impacts (health risks) physically and psychologically and it denotes null hypothesis is accepted and the level of significance is .000 . There is no positive relationship between education and sedentary life style.

\section{FINDINGS OF THE STUDY}

- $96 \%$ of the respondent's job life style are sedentary in nature. $65 \%$ of respondents are not aware that sedentary lifestyle causes huge ill impacts physically and psychologically.

- $37 \%$ of employees are aware and $50 \%$ of are not aware that sedentary life style is associated with elevated perceived stress. $98 \%$ of the respondents are those who sit in front of the computer to work the whole day.

- $99 \%$ of the respondents are opinioned that in IT organization it is mandatory for employees to work in a lifestyle that is sedentary in nature.

- $32 \%$ of respondents feel that male employees are mostly affected due to sedentary lifestyle, $42 \%$ of respondents feel that female employees are mostly affected due to sedentary lifestyle.

- $16 \%$ of the respondents gained more Wight than the actual BMI (Body Mass Index). $42 \%$ of them are perfect in their weight. $26 \%$ of the respondents are under their actual BMI and $15 \%$ of the respondents are not having any idea towards their weight relevant with BMI.

- $46 \%$ of the respondents are highly stressed due to the sedentary work style that they undergo. $56 \%$ of the respondents are experienced INSOMNIA (sleeplessness) or poor sleeping habits/sleep disturbances which are due to the stress and sedentary lifestyle.

- $56 \%$ of the respondents understood that sedentary lifestyle is associated with many vitamin deficiency and consequences such as hypertension osteoarthritis.

- $38 \%$ of the employees undergo regular master health check up to make sure that they are healthy enough in all scenarios. $45 \%$ of the employees stated that the people around them feel physically inactive

- $49 \%$ of the employees feel that sedentary lifestyle makes them lazy, sluggish and lethargic.

- $36 \%$ of the respondents strongly agreed that they are unhappy with the sedentary lifestyle

- $55 \%$ of the respondents strongly agreed that the continuous stress to eyes to computers causes eyesight problems in young age. $55 \%$ of the respondents agreed that they have a bloated tummy or heavy abdominal muscle mass as the result of sedentary lifestyle. $51 \%$ of the respondents strongly agreed that they experienced poor metabolism, poor bowel movements or constipation.

- Majority of the employees experienced fatigue or tired after work hours and stiffness in the muscle. Majority of the respondents don't do any activities like Brisk walking/jogging, Cycling, Yoga, Aerobics, zumba and acrobatics.

- $63 \%$ of the respondents work 3-6 hours per day over the computer systematically. Majority of the respondents use to have Cheesy sandwich/pizzas as snacks during their lunch breaks and they used to consume 2-4litres of water per day.

\section{SUGGESTIONS}

- Some employees may be workaholic where they could never move from their work desk. They could not find the ambience for relaxing which means a suitable place to relax or go for a walk. This has to considered and produced by the organization to the employees to make a change in their sedentary behavior.

- The optimal temperature is also another environmental factor that has to be taken into consideration. The temperature has to be maintained in such a way it balances the external environment up to certain extent.

- The employees have to be facilitated with stress buster activities in the work place which could help them to reveal from their sedentary behavior to certain level. These stress buster activities could also enable the employees to relax and proceed their work with comprehensive efficiency. In other way the work could also be made effective by assigning substitutes during the relaxation time. In this way the employee could relax and stay health and also the work could be effectively completed. In this way the organization could provide opportunity to many employees for the healthy living of the employees. This could enable the employees to take regular break for refreshment. The worst case includes, the employees could be workaholic and they would ignore their physically necessary attributes like using the toilet etc. these things can be avoided only by the organizations facilitation.

- The organization can provide healthy snacks like sprouts, malt, organic tea, etc. rather unhealthy chats or beverages.

- The organization should also consider to provide training of the eye relaxation exercises and exercises to reduce muscle stiffness so that employees could do and get relaxed with the stiffness in the muscle and joints. These changes in the consideration of the employees in the workplace could create a great asset to the organization as this could eliminate the risk of Anxiety, Metabolic disorders, Nerve related problems, Cardio vascular disease and other heart related issues, Diabetes (type1 and type2), Obesity, Vitamin deficiency, Abdominal distension, Blotted tummy, Low energy level, Joint swelling, Accumulation of excess calories and hence unsaturated fatty acids etc.

\section{CONCLUSION}

This paper gives us an elaborate understanding on the various difficulties and health impacts that the IT employees are subjected to and the various remedial actions that can be performed to avoid these negative health effects. And this implies that there is a positive relationship between sedentary lifestyle and elevated stress. This study will create awareness to the employees on the consequences they would face due to the sedentary behavior. The cause for the ill effects cannot be subjected only to the organization or only to the employees. The employees have to take the necessary actions while the organization facilitates accordingly. Both the organization

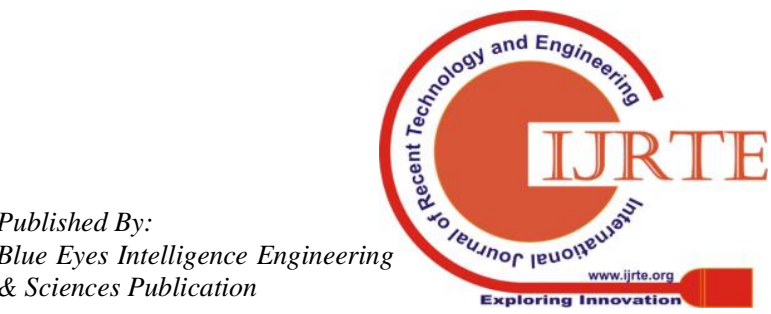


and the employees should act as the pitch and the timbre to play successful music i.e. to stay healthy.

\section{REFERENCES}

1. Akindutire. Isaac OlusolaOlanipekun, Johnson Adetunji (2017) "Sedentary Life-Style as Inhibition to Good Quality of Life and Longevity" Journal of Education and Practice www.iiste.org ISSN 2222-1735 (Paper) ISSN 2222-288X (Online) Vol.8, No.13, 2017

2. Abhinav Singh and BharathiPurohit(2012) "Physical Activity, Sedentary Lifestyle, and Obesity Among Indian Dental Professionals "Journal of Physical Activity and Health, 2012, 9, 563-570 2012 Human Kinetics, Inc

3. Andre Ramalho, Joao Petrica, Antonio Rosado(2018) "Sedentary behaviors and psychological outcomes among older adults: a systematic review" MotricidadeEdiçoesDesafio Singular 2018, vol. 14, n. 1, pp. 73-85Caio Victor de Sousa, Marcelo MagalhaesSales(2014) "Sedentary Life Style is Associated with an Elevated Perceived Stress" Journal of Exercise Physiology online December 2014 Volume 17 Number 6 Official Research Journal of the American Society of Exercise Physiologists ISSN 1097-9751

4. Eero A. Haapala, JuusoVaisto (2017) "Physical activity and sedentary time in relation to academic achievement in children" Journal of Science and Medicine in Sport 20 (2017) 583-589

5. HarriHelajarvi(2016) "Sedentary Behaviour And Health With Special Reference to obesity and Fatty Liver in Early Midlife The Cardiovascular Risk in Young Finns Study" ISSN 0355-9483 PainosalamaOy - Turku, Finland 2016

6. Leo Pruimboom, Charles L. Raison, and Frits A. J. Muskiet (2015)" Physical Activity Protects the Human Brain against Metabolic Stress Induced by a Postprandial and Chronic Inflammation" Hindawi Publishing Corporation Behavioural Neurology Volume 2015, Article ID 569869

7. Dr.Seema G Chawardol1, Dr.BhagwatiTripathi, Dr.Jinesh Kumar Jain, (2018) "Sedentary Lifestyle Induced Insomnia; Causes and Management" World Journal of Pharmacy and Pharmaceutical Sciences Volume 7, Issue 3, 1279-1283 Review Article ISSN 2278 4357

8. Dr.Mfrekemfon P. Inyang and Okey-Orji, Stella(2015)"Sedentary Lifestyle: Health Implications" IOSR Journal of Nursing and Health Science (IOSR-JNHS) e-ISSN: 2320-1959.p- ISSN: 2320-1940 Volume 4, Issue 2 Ver. I (Mar.-Apr. 2015), PP 20-25

9. Larissa CasteloGuedesMartinsI, Marcos Venícios de Oliveira lopes (2015) "Sedentary lifestyle in individuals with hypertension". Rev Bras Enferm. 2015; 68(6):697-704. DOI: http://dx.doi.org/10.1590/0034-7167.2015680602i

10. Leandro Fornias Machado de Rezende, Mauricio Rodrigues Lopes(2014) "Sedentary Behavior and Health Outcomes: An Overview of SystematicReviews". PLoS ONE 9(8): e105620. doi:10.1371/journal.pone.0105620

11. Margot Shields and Mark S. Tremblay(2008) "Sedentary behaviour and obesity"Component of Statistics Canada Catalogue no. 82-003-X Health Reports

12. SeptiViantriKurdaningsih, Toto Sudargo, Lely Lusmilasari(2016) "Physical activity and sedentary lifestyle towards teenagers" overweight/obesity status" International Journal of community Medicine and Public Health Kurdaningsih SV et al. Int J Community Med Public Health. 2016 Mar;3(3):630-635 http://www.ijcmph.com ISSN 2394-6032 | eISSN 2394-6040 